\title{
Bilateral diaphragmatic paralysis after kidney surgery
}

\author{
S. Sozzo, P. Carratù, M.F. Damiani, V.A. Falcone, \\ A. Palumbo, S. Dragonieri, O. Resta
}

\begin{abstract}
Bilateral diaphragmatic paralysis after kidney surgery. S. Sozzo, P. Carratù, M.F. Damiani, V.A. Falcone, A. Palumbo, S. Dragonieri, O. Resta.

A 57-year-old woman underwent an enucleoresection of her right kidney angiomyolipoma. Two weeks later she was admitted to our hospital because of dyspnea at rest with orthopnea. The chest $x$-ray showed the elevation of both hemidiaphragms and the measurement of the sniff transdiaphragmatic pressure confirmed the diagnosis of bilateral diaphrag-
\end{abstract}

matic paralysis. A diaphragm paralysis can be ascribed to several causes, i.e. trauma, compressive events, inflammations, neuropathies, or it can be idiopathic. In this case, it was very likely that the patient suffered from post-surgery neuralgic amyotrophy. To our knowledge, there are only a few reported cases of neuralgic amyotrophy, also known as Parsonage-Turner Syndrome, which affects only the phrenic nerve as a consequence of a surgery in an anatomically distant site. Monaldi Arch Chest Dis 2012; 77: 2, 102-104.

Keywords: Diaphragmatic paralysis, Kidney surgery.

Institute of Pulmonary Disease, University of Bari, Italy.

Correspondence: Dr. Pierluigi Carratù, Institute of Pulmonary Disease, University of Bari, Piazza G. Cesare 12, 70100 Bari, Italy; e-mail: pierluigicarratu@yahoo.com

\section{Introduction}

Diaphragm paralysis as a result of a surgery is usually due to a direct trauma suffered by the phrenic nerve or by the diaphragm itself. However, if the surgery is performed in a site anatomically distant from the diaphragm, it is reasonable to suspect a different cause. In the present report, we describe the case of a woman who, after surgery on her right kidney, developed a rare form of neuralgic amyotrophy. To our knowledge, there are very few documented cases of bilateral diaphragmatic paralysis secondary to kidney surgery.

\section{Case report}

A 57-year-old non-smoker woman underwent an enucleoresection of the right kidney angiomyolipoma. Two weeks later she was admitted to our hospital because of dyspnea at rest with orthopnea. Upon physical examination, she was conscious, obese, kyphoscoliotic and dyspnoic while sitting or standing. In supine position, a worsening of dyspnea was observed, together with a paradoxic movement of the abdomen during inspiration. Respiratory rate was $20 \mathrm{bpm}$ and heart rate was 100 $\mathrm{bpm}$. Arterial blood gas values (in supine position, breathing room air) were the following: $\mathrm{pH} 7.44$, $\mathrm{pO}_{2} 54.4 \mathrm{mmHg}, \mathrm{pCO}_{2} 60 \mathrm{mmHg}, \mathrm{SO}_{2} 87 \%$ and the alveolar-arterial oxygen gradient was normal $(22.4 \mathrm{mmHg})$. Such haemogasanalytic results suggested an alveolar hypoventilation. Laboratory findings were in the normal range. Spirometry performed in orthostatism indicated a severe restric- tive process (TLC $48.6 \%$ of predicted, VC $42.2 \%$ of predicted, $\mathrm{FEV}_{1} 43.8 \%$ of predicted, $\mathrm{FEV}_{1} / \mathrm{VC}$ $87.29 \%$ that is $111.3 \%$ of predicted), but the results obtained with the patient in the supine position were not reliable because of poor cooperation by the woman due to worsening of dyspnea in clinostatism. The chest $\mathrm{x}$-ray showed an elevation of both hemidiaphragms with basal areas of distelectasis, in addition to an almost absent diaphragmatic excursion in the passage from a deep inspiration to a deep expiration phase (figure 1a and $1 \mathrm{~b}$ ). The CT scan did not provide any further information. Suspecting a bilateral diaphragmatic paralysis, the patient underwent the respiratory muscle tests: the maximal static inspiratory pressure (PImax) was $20 \mathrm{~cm} \mathrm{H}_{2} \mathrm{O}$ (27\% of predicted), the maximal static expiratory pressure (PEmax) was $37 \mathrm{cmH}_{2} \mathrm{O}(45 \%$ of predicted) and the sniff transdiaphragmatic pressure (SnPdi) was $7.9 \mathrm{cmH}_{2} \mathrm{O}$, with a reference range of 82-204 $\mathrm{cm} \mathrm{H}_{2} \mathrm{O}$ [1]. It was not possible to perform either electromyography or electric stimulation of the phrenic nerve due to the interference caused by the abundant adipose tissue of the patient: her body mass index (BMI) was $34.5 \mathrm{~kg} / \mathrm{m}^{2}$. Polysomnography (performed by the device e-Series Compumedics) has pointed out the presence of long phases of reduction of nasal flow, asynchrony of thoracoabdominal movements (without any apnoic and/or hypopnoic event) as well as tonic desaturations (TST90 30\%) (fig. 2). The results were compatible with sleep-hypoventilation. The same test, carried out the following night with the patient under ventilation therapy with BiPAP, marked the total disappearance of hypoventilation episodes 


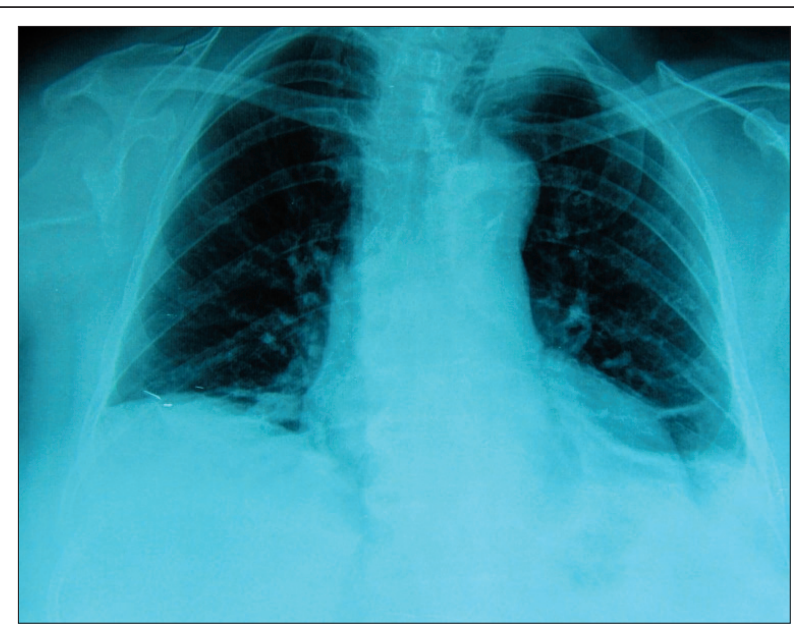

Fig. 1a. - Chest x-ray performed during a deep inspiration. It is possible to see the elevation of both hemidiaphragms with basal areas of distelectasis.

in addition to an oxygen saturation constantly above $90 \%$. A diagnosis of bilateral diaphragmatic paralysis secondary to kidney surgery has been formulated. The patient was discharged from our hospital with nocturnal intermittent positive pressure ventilation and with rehabilitation respiratory programs. After one year, an improvement of symptoms, haemogasanalytic values and respiratory muscle tests has been recorded. However, spirometry values were still almost the same and the patient continued needing nocturnal ventilation therapy.

\section{Discussion}

We described the case of a 57-year-old woman who, after right kidney surgery, developed a bilateral paralysis of the diaphragm. This diaphragmatic paralysis, first suspected on the basis of clinical presentation, spirometric findings, and chest x-ray, was then confirmed by respiratory muscle tests. A hallmark of this disease is the paradoxic inward

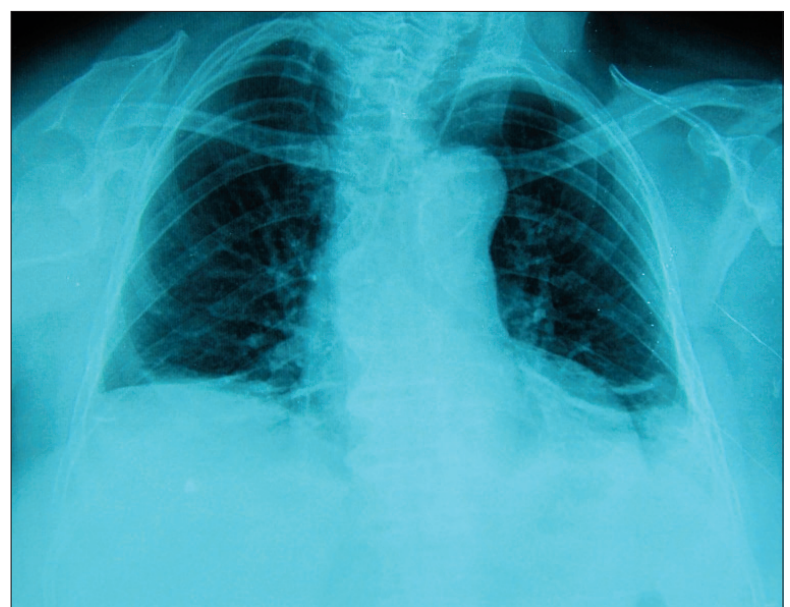

Fig. 1b. - Chest x-ray performed during a deep expiration. There is an almost absent diaphragmatic excursion in the passage from a deep inspiration to a deep expiration phase.

movement of the abdomen, visible in supine position during inspiration [2], as it was observed in our patient. As far as the pulmonary function tests are concerned, literature reports that, in patients with bilateral paralysis, a reduction of $\mathrm{VC}(45 \%$ of predicted), $\mathrm{FEV}_{1}$ (50\% of predicted) and TLC (55\% of predicted) is detected [3]. These values match those of our patient. Chest X-rays are a poor diagnostic tool for the diagnosis of diaphragmatic paralysis [4]. Though PImax measurement is of considerable help when diagnosing the bilateral paralysis of diaphragm, the diagnostic gold standard is represented by the objective measurement of the transdiaphragmatic pressure [5, 6]. Although we could not perform the electric stimulation of the phrenic nerve, measuring Pdi during a maximal sniff, together with all other tests, led to a diagnosis.

A diaphragm paralysis can be ascribed to several causes, i.e. trauma, compressive events, inflammations, neuropathies, or it can be idiopathic [3]. In this case we excluded whatever compressive cause, because the patient had never suffered from cervical osteoarthritis and the CT scan had shown no expansive process of lung or mediastinum. Symptoms and laboratory results did not support the presence of inflammation. Considering that the site of the surgery was anatomically distant from diaphragm, a direct trauma suffered by the diaphragm or the phrenic nerve was unlikely. Moreover, neither during nor soon after the surgery, the patient un-
Fig. 2. - Polysomnography graphic showed the presence of long phases of reduction of nasal flow, asynchrony of thoracoabdominal movements (without any apnoic and/or hypopnoic event) and tonic desaturations. 
derwent central venous catheter insertion, another possible cause for diaphragm paralysis [7]. Therefore, it was very likely that the patient suffered with a post-surgery neuralgic amyotrophy.

Neuralgic amyotrophy, also known as Parsonage-Turner Syndrome, generally starts with a pain in the shoulder region that subsequently irradiates to the ipsilateral arm. In some cases, also the phrenic nerve is involved [8].

To our knowledge, literature reports several cases of both post-surgery neuralgic amyotrophy and neuralgic amyotrophy involving only the phrenic nerve. On the other hand, there are few cases of Parsonage-Turner Syndrome which affects only the phrenic nerve as a consequence of a surgery in an anatomically distant site [4, 7]. Patients with diaphragm bilateral paralysis and respiratory insufficiency are generally treated with intermittent positive pressure ventilation [10]. A surgical alternative is represented by diaphragm plication, even though this method does not seem to allow the weaning from ventilation when adults [11].

In conclusion, in the presence of a diaphragm bilateral paralysis, in patients recently operated in an anatomically distant site, it is reasonable to suspect a neuralgic amyotrophy of the phrenic nerve. The treatment with BiPAP results in an improved quality of life.

\section{References}

1. American Thoracic Society/European Respiratory Society. ATS/ERS Statement on respiratory muscle testing. Am J Respir Crit Care Med 2002; 166: 518-624.

2. Syabbalo N. Assessment of respiratory muscle function and strength. Postgrad Med J 1998; 74: 208-15.

3. Qureshi A. Diaphragm paralysis. Semin Respir Crit Care Med 2009; 30: 315-20.

4. Chetta A, Rehman AK, Moxham J, Carr DH, Polkey MI. Chest radiography cannot predict diaphragm function. Respir Med 2005; 99: 39-44.

5. Celli BR. Respiratory management of diaphragm paralysis. Semin Respir Crit Care Med 2002; 23: 275-81.

6. McCool FD, Tzelepis GE. Dysfunction of the diaphragm. N Engl J Med 2012 8; 366: 932-42.

7. Moore AJ, Moxham J, Polkey MI. Diaphragm weakness as a cause of breathlessness after anatomically distant surgery. Thorax 2005; 60: 786-7.

8. Lahrmann H, Grisold W, Authier FJ, Zifko UA. Neuralgic amyotrophy with phrenic nerve involvement. Muscle Nerve 1999; 22: 437-42.

9. Chetta A, Aiello M, Olivieri D. Diaphragm paralysis after nephrectomy. Thorax 2006; 61: 549.

10. Fernández Vázquez E, Sáez Roca G, Valdivia Salas MM. Idiopathic bilateral diaphragm paralysis: Bi-PAP treatment. Arch Bronconeumol 2002; 38: 252.

11. Simansky DA, Paley M, Refaely Y, Yellin A. Diaphragm plication following phrenic nerve injury: a comparison of paediatric and adult patients. Thorax 2002; 57: 613-6.

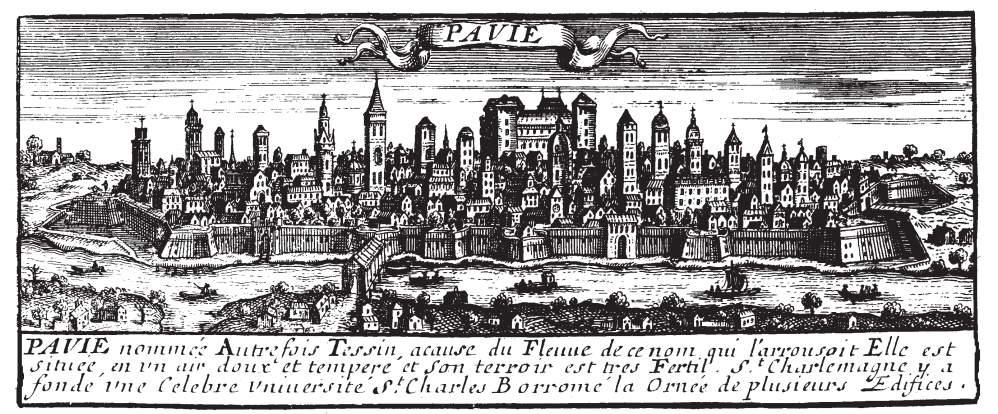

